\title{
Transitioning to E-Learning during the COVID-19 pandemic: How have Higher Education Institutions responded to the challenge?
}

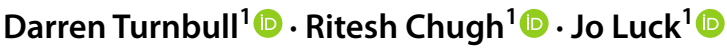

Received: 31 May 2021 / Accepted: 9 June 2021 / Published online: 23 June 2021

(c) The Author(s), under exclusive licence to Springer Science+Business Media, LLC, part of Springer Nature 2021

\begin{abstract}
Lockdowns, social distancing, and COVID safe hygiene practices have rendered the usual face-to-face course delivery options all but impossible for many higher education institutions worldwide. A forced transition to online learning has been the only viable option for preventing a wholesale closure of many institutions. The aim of this study is to identify the role of educational technologies in the transition from face-to-face to online teaching and learning activities during the COVID-19 pandemic. This paper identified five challenges to transitioning to online education experienced by higher education institutions: synchronous/asynchronous learning tool integration, access to technology, faculty and student online competence, academic dishonesty, and privacy and confidentiality. From the studies examined in this literature review, strategies for successful online implementation were also noted. These included: providing e-learning training support for faculty and students, fostering online learning communities, and expanding traditional face-to-face course delivery to incorporate more elements of blended learning. A Technology Enhanced Learning Hub that encapsulates the learning process within a modality-neutral learning space is presented as a suggested framework for delivering higher education programs in this challenging environment.
\end{abstract}

Keywords COVID-19 · Educational technology · Transition · E-Learning · Literature review $\cdot$ Online learning

Darren Turnbull

d.turnbull@cqu.edu.au

Ritesh Chugh

r.chugh@cqu.edu.au

Jo Luck

j.luck@cqu.edu.au

1 Central Queensland University, 16 Bruce Highway, North Rockhampton, QLD 4702, Australia 


\section{Introduction}

The entrenchment of the COVID-19 pandemic in the daily lives of billions of people across the world has profoundly impacted the way activities are carried out involving human-to-human interactions that pre-COVID rarely required a second thought now require careful pre-planning before they can be carried out. Higher education institutions (HEIs) have also been caught up in this new mode of social interplay. They have had to rapidly adapt to an environment where traditional face-to-face (F2F) classroom environments are significantly more challenging (Bryson \& Andres, 2020).

The impact that this has had on the way that courses are designed and delivered in HEIs has been significant. Government instigated lockdowns have disrupted once-thriving classroom environments, forcing education providers to rapidly deploy online learning technologies to facilitate engagement with learners remotely. This has led to the creative deployment of learning and communication platforms that have profoundly transformed the teaching and learning landscape for disciplines and institutions that traditionally were thought of as being conducted in a physical environment. The challenge in such circumstances is often centred around an institutional requirement to replicate physical classrooms online using existing distance education infrastructure (Arasaratnam-Smith \& Northcote, 2017). While there have been attempts to document the efforts of individual institutions to transition to online learning during this pandemic, a comprehensive picture of the global significance of these efforts is missing. This study contributes to closing that gap.

The overarching aim of this study is to identify the role of educational technologies in the transition from F2F to online teaching and learning activities during the COVID-19 pandemic. Four specific research questions (RQ) were identified to drive the research effort. These are:

RQ1: How did educational technologies assist in the transition?

RQ2: What were the challenges staff and students encountered in the transition?

RQ3: Which educational technologies were utilised the most?

RQ4: What are the lessons learnt in the transition?

Information technology (IT) tools and other infrastructure used to support higher education can be classified into two broad camps: asynchronous and synchronous (Larasati \& Santoso, 2017; Lim, 2017). Asynchronous learning systems are built on communication platforms that do not require time-sensitive interactions between stakeholders in the education process (Larasati \& Santoso, 2017). Learning Management Systems (LMSs) such as Moodle and Blackboard are examples of well-established distance learning platforms that are structured to facilitate stakeholder interactions based on a 'request-response' framework unconstrained by time limitations. On the other hand, synchronous online learning involving the real-time interchange of information is usually conducted via 
video conferencing tools such as Zoom and Skype (Janghorban et al., 2014; Kohnke \& Moorhouse, 2020). These have been pivotal to the efforts of most HEIs to recreate classroom environments online. However, a combination of the two modes of engagement is necessary to replicate all F2F instructional activities in a purely online environment (McDaniels et al., 2016).

Central to concerns of transitioning F2F education to online delivery are the teaching practices and administrative support required to sustain meaningful student engagement (Wingo et al., 2017). Such considerations are often rooted in the discipline being taught and the characteristics of target learners. For example, medicine and other health-related courses that have a practical component would require very different teaching approaches and learning resources to a training program in advanced statistical techniques. In an online environment, what was once very easy to accomplish F2F like practical demonstrations, becomes quite challenging requiring subject matter experts to become adept at the use of rapidly evolving learning technologies that are not commonly used to teach hands-on activities in their field (Mitchell, 2020).

A useful framework that encapsulates the knowledge and skill demands of contemporary educators is the technological pedagogical content knowledge model (TPACK) (Archambault \& Barnett, 2010; Cox \& Graham, 2009; Jang \& Tsai, 2013). Figure 1 displays TPACK's triad of interrelated teaching knowledge: pedagogy, content, and technology. Pedagogy often refers to the teacherfocused approach to educating children and is in contrast to adult learning principles embedded in andragogy which ideally involves the voluntary commitment of learners to pursue knowledge for its intrinsic value (Pew, 2007). The second element of the model, content, encompasses specific knowledge domains of education such as health, engineering, or law. Technology includes all of the tools, software, and hardware necessary to facilitate online learning. It is through this three-way lens that this study situates the findings of selected papers analysing the COVID-19 pandemic induced transition experiences of HEIs in different countries.

Fig. 1 TPACK model

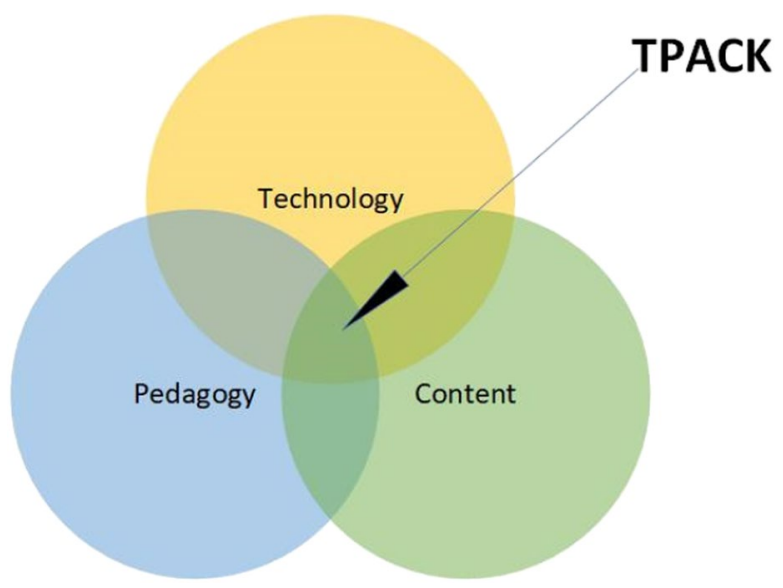




\section{Method}

Many methodologies can be employed to construct a review of available literature. One commonly accepted approach is to explore literature related to a topic of interest as broadly and comprehensively as possible, capturing a wide range of articles and views on a research question of interest. This approach is often referred to as a narrative review but is often criticised for lacking rigour in terms of strategies and rules adopted to search for the literature of interest (Collins \& Fauser, 2005). A more robust and quantifiable search methodology is the systematic review. This type of literature review requires the development of a search protocol that describes definitions, search strings, search strategies, inclusion and exclusion criteria, and an approach to synthesising extracted information (Mallett et al., 2012). This study's chosen methodology, often referred to as an integrative review, is based on a research strategy that attempts to locate and situate literature within an identified framework (Torraco, 2016). It draws on some of the rigour of systematic reviews in terms of search strategies and inclusion and exclusion criteria, but maintains a sufficiently broad focus to ensure that the multifaceted characteristics of the TPACK framework are fully considered.

The databases used in this review were sourced from the following search engines: Ebsco (35 databases), Gale (28 databases), Informit (33 databases), and Proquest (40 databases). Only English language peer-reviewed journal articles based on the COVID-19 pandemic-related issues were included. A date range of 1 February 2020 to 30 October 2020 was applied to all searches. All included articles reported on studies that were instigated in response to changes to educational design and delivery at universities caused by restrictions to F2F instruction as a consequence of COVID-19. Table 1 displays the search terms, including synonyms, used in each of the four search engines.

A total of fifty-two unique papers were initially identified from the database search. After careful examination of each paper, studies that did not report empirical findings or were not directly related to the transition of higher education programs to online learning during COVID-19 were removed from the list. The final tally of included articles was twenty-six.

Table 1 Search engine keywords

\begin{tabular}{|c|c|c|c|c|}
\hline Keyword & Synonym 1 & Synonym 2 & Synonym 3 & Synonym 4 \\
\hline Educational Technology & $\begin{array}{l}\text { Learning manage- } \\
\text { ment system }\end{array}$ & Learning technology & $\begin{array}{l}\text { Instructional } \\
\text { Technology }\end{array}$ & \\
\hline Teaching and Learning & Education & Training & & \\
\hline Face to Face & $\mathrm{F} 2 \mathrm{~F}$ & Face-to-Face & & \\
\hline Online & e-learning & elearning & & \\
\hline Transition & Change & Shift* & Adapt* & Move* \\
\hline COVID-19 & COVID19 & COVID* & Pandemic & Corona* \\
\hline Role & Function* & Operation* & Purpose* & \\
\hline
\end{tabular}




\section{Results}

Table 2 provides an overview of the selected studies, including their region of origin and broad discipline area. Each paper was classified according to its region of origin and discipline-focus. The USA and China were designated as nation-state regions because they had sufficient papers to justify a separate grouping. The discipline areas assigned to each study included a general category which refers to papers that did not specifically address any specific subject area in higher education.

The distribution of studies by subject area and region is shown in Fig. 2. The $\mathrm{X}$-axis categories relate to the broad discipline area of each study. These categories are further divided into regional locations where the studies were conducted.

The largest subject area categories were 'Health-Related' and 'General. The general category in this analysis refers to studies that were not based on any particular academic discipline area. It is to be expected that health-related articles would feature prominently in this review because of the greater awareness of faculty and students in these disciplines to COVID-related issues. The next highest number of studies were related to the subject area: English for Academic purposes (EAP). This category includes all courses related to the teaching of English language skills for academic purposes. These studies originated from all regions except the subcontinent and the UK.

European studies had the largest number of papers in this review, although there were no papers in this region that dealt explicitly with EAP or Science \& Engineering programs. The majority of Middle East papers were general in nature but included two humanities-related articles and one study each on education and health-related areas. It is interesting to note that there was only one paper each from India and Australasia that met the inclusion criteria for this review (see method section). While there are certainly many studies conducted in both these countries on COVID-19 related issues, there were none that met the strict condition of being primarily instigated by COVID events and included an adequate analysis of the impact and implications for university education in their chosen area.

The types of technologies referred to in the papers was also investigated. A word frequency analysis of the PDF manuscripts was conducted to determine the most popular words employed in the text of each paper. Based on this analysis, the top eleven mentions of popular platforms are presented in Fig. 3.

The most commonly mentioned platform was Zoom, included in 14 papers. YouTube and Moodle were the next most common platforms cited in ten papers each. Google-related software such as Google classroom (4 papers) and Google Docs ( 2 papers) were not widely referred to in the studies. The reason for this could be the association of the Google brand-name with internet technology in general rather than any specific function such as Zoom for videoconferencing and Moodle for online learning. 


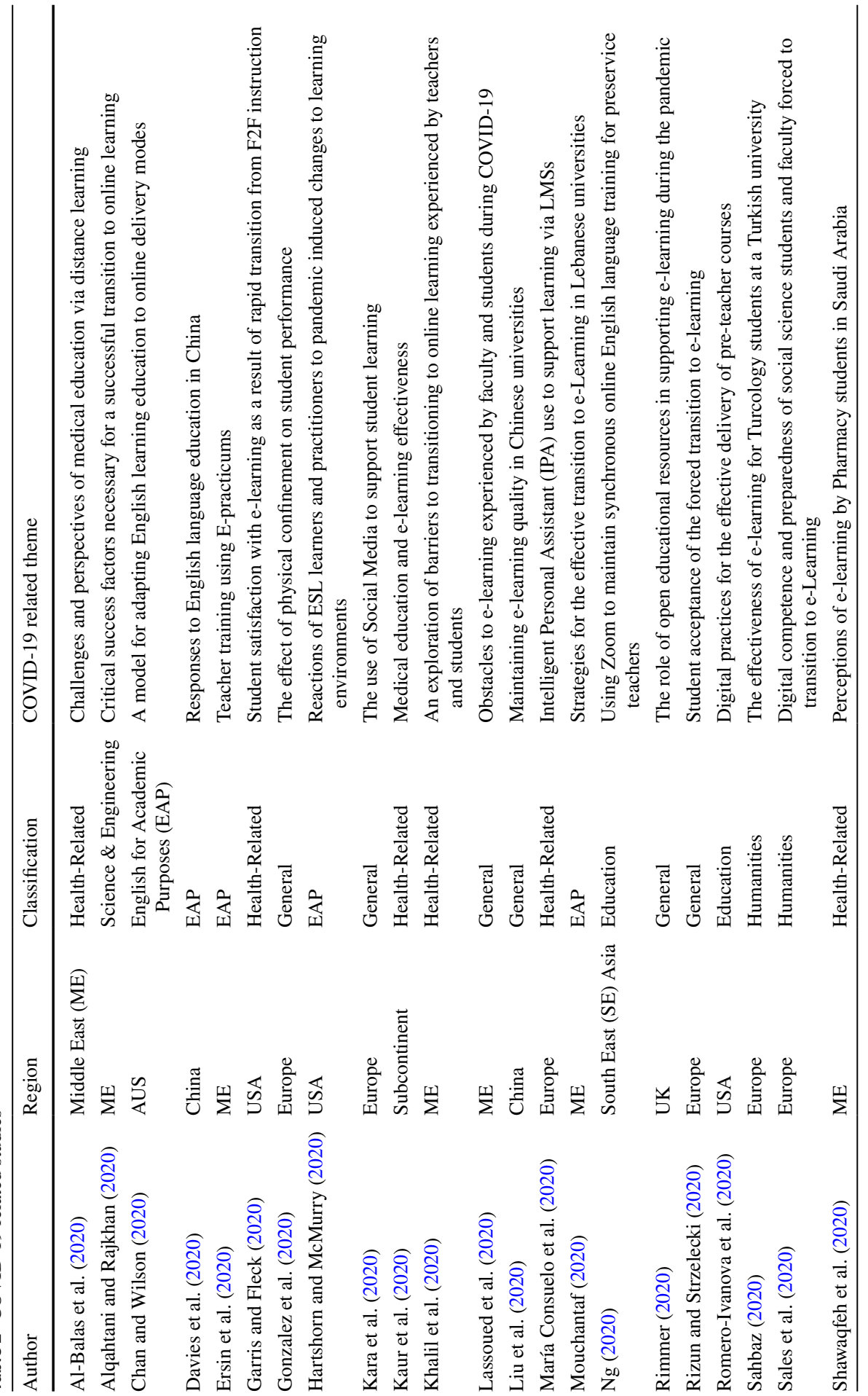




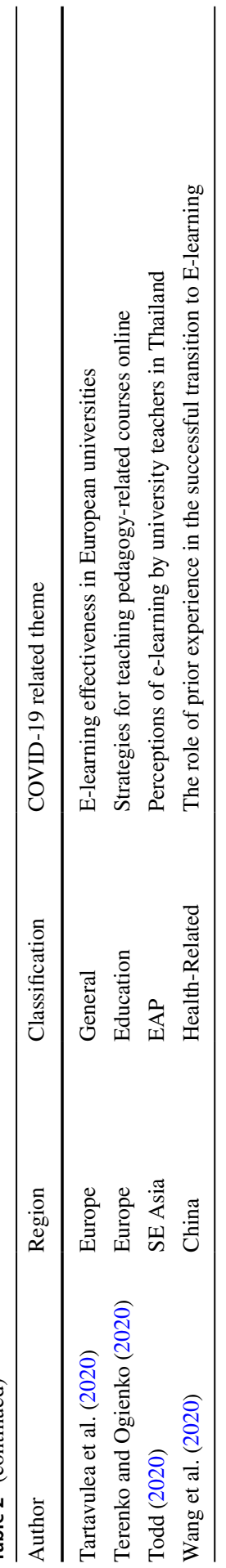




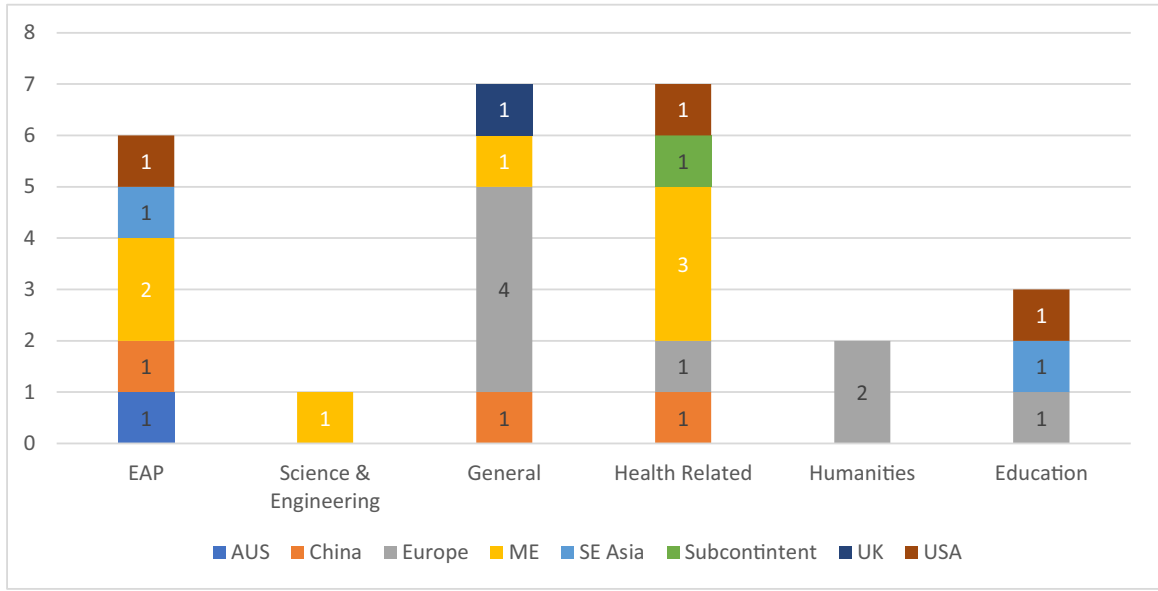

Fig. 2 Distribution of studies by subject area and region

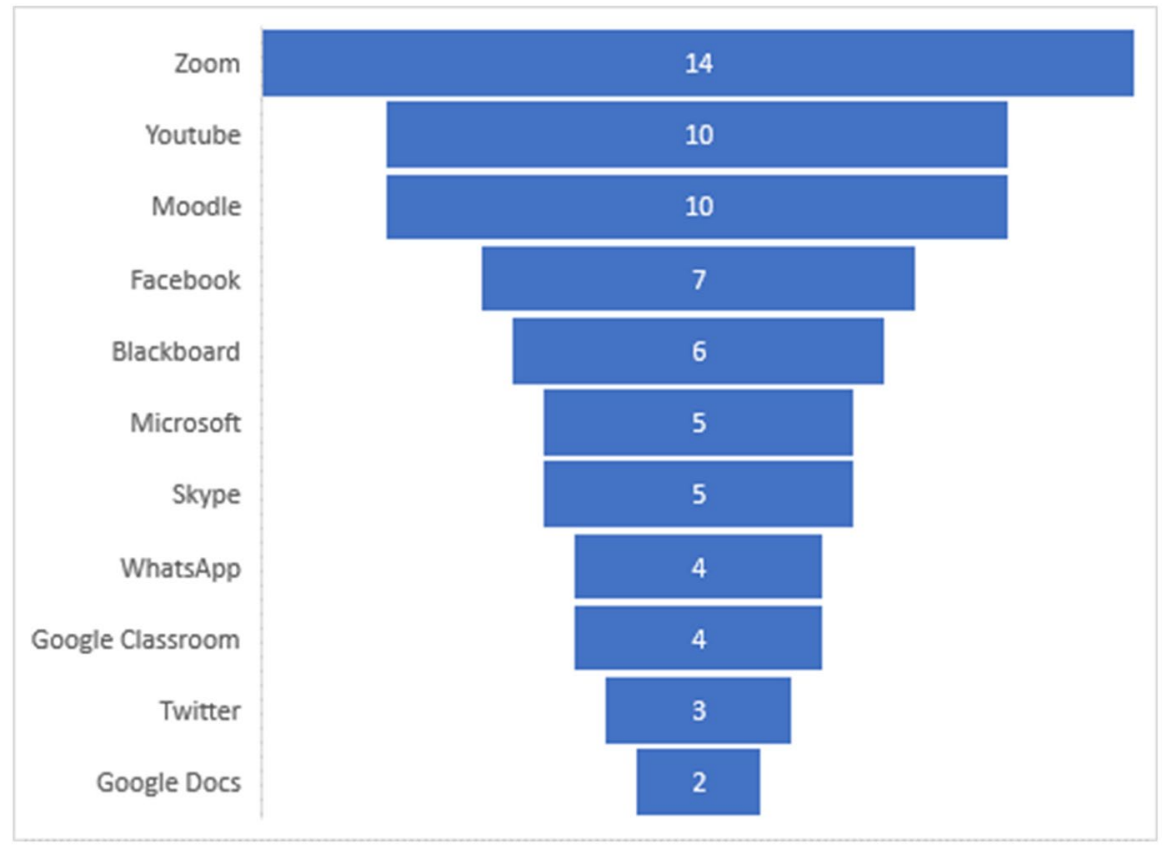

Fig. 3 Eleven most mentioned technologies 


\section{Findings and discussion}

\subsection{Technologies used in the transition}

\subsubsection{Replicating classrooms in cyberspace: the role of Zoom in this transition}

Recreating physical learning spaces in cyberspace was a common approach to dealing with in-class engagement issues. Zoom featured as a popular tool for replicating F2F instruction online. In the area of English language instruction, researchers demonstrated how this tool could be used to conduct classes with students who were accustomed to more traditional in-class delivery methods (Davies et al., 2020; Hartshorn \& McMurry, 2020; Ng, 2020; Todd, 2020) The successful use of Zoom to reproduce classroom teaching practice for delivering preservice teacher training is also demonstrated in two studies (Ersin et al., 2020; RomeroIvanova et al., 2020). Interestingly, Zoom was also used to support medical education programs in Jordan (Al-Balas et al., 2020) and Saudi Arabia (Khalil et al., 2020). However, poor internet connection and the cellular data package limitations were cited as impediments to seamless Zoom deployment. Garris and Fleck (2020)'s study of psychology student perceptions of online learning highlighted the lack of familiarity with synchronous tools like Zoom among learners who are accustomed to asynchronous approaches to online learning, as a factor to be explored when evaluating online learning efficacy. The use of synchronous and asynchronous tools in education should be viewed as complementary (Teng et al., 2012) so appropriate support systems that recognise this co-dependency will benefit learners as they adjust to new ways of interacting with HEIs.

\subsubsection{Adapting LMSs to their new central role as "first points of access"}

LMSs have traditionally served a central role in facilitating access to online learning spaces and coordinating assessments (Pilli, 2014; Subramanian et al., 2014; Turnbull et al., 2019). However, LMSs are largely designed to function asynchronously (Ngom et al., 2012), and many students have only experienced their use as a tool to assist blended learning in a classroom environment. Moodle was the main platform for conducting asynchronous learning activities in studies that examined the use of online tools in specific courses and programs (Davies et al., 2020; Gonzalez et al., 2020; Lassoued et al., 2020; Rizun \& Strzelecki, 2020; Terenko \& Ogienko, 2020; Wang et al., 2020). However, Moodle was never used by itself as the only weapon in the teacher's online arsenal and was often supplemented by videoconferencing tools such as Zoom in Terenko and Ogienko (2020)'s study of online pedagogy courses. One innovative study explored the use of an intelligent personal assistant (IPA) which was embedded in a LMS (María Consuelo et al., 2020). Health science students were able to synchronously interact with the IPA to find answers to questions in real-time rather than posting to chat forums and bulletin boards which may or may not receive a response. The 
study acknowledges the central role of LMSs in managing curriculum and student progress while recognising that without additional functionality that can facilitate real-time communication, engagement with such systems is challenging in a purely online learning environment.

\subsubsection{The use of social media in online delivery}

Social Media (SM) is a well-established gateway to communicating with students who are usually frequent users of this communication interface. SM has a role in delivering teaching resources, communicating with stakeholders, and facilitating collaboration (Chugh \& Ruhi, 2017). During the pandemic period under review, Facebook was the most popular SM exploited in the transition to online learning (Al-Balas et al., 2020; Kara et al., 2020; Lassoued et al., 2020; Rizun \& Strzelecki, 2020; Uzzaman et al., 2020), perhaps because of its capability to represent classroom interactions in a familiar online form. However, SM by itself may not replace the social interactions learners are accustomed to in F2F situations as Liu et al. (2020)'s study of the transition to online learning of a Chinese university attests. Moreover, there are significant barriers to SM use in HE such as assessment submission integrity, privacy limitations, limited integration with institutional LMSs (Chugh \& Ruhi, 2019), that limit its deployment as a standalone environment. There is perhaps a place for SM in online course delivery provided that it can be augmented with structured materials and reliable assessment protocols.

\subsection{Online transition challenges}

\subsubsection{Reconciling synchronous/asynchronous delivery}

In a blended learning situation, communication naturally takes place in both synchronous and asynchronous ways. For example, a question-and-answer session in a class tutorial is an example of real-time communication, whereas the posting of assessment requirements on a university notice board is a form of communication that is not time-sensitive. In an online environment, it would be ideal to take advantage of both forms of communication in course delivery (Lowenthal et al., 2017). As reported in Davies et al. (2020)'s study of institutional responses to COVID-19 at four Chinese universities, students appreciated the flexibility and trust that asynchronous course delivery gave them to manage their studies. An alternate view presented by Romero-Ivanova et al. (2020)'s participants in her study of digital practice during COVID-19 was that synchronous tools such as Zoom are invaluable in sustaining a sense of connectedness in an otherwise isolated situation. Both faculty and HEIs have to carefully consider the capacity of ICT tools to support both modes of communication before integrating them into course delivery systems. This will also depend on the demands of the course content, student motivation and needs, and available technical support (Watts, 2016). 


\subsubsection{Technology access}

The technical issues that may confront students in online learning situations are dependent on many factors, such as the quality of communications infrastructure and the availability and access to software and hardware platforms to support learning. One of the most fundamental obstacles to transitioning to online learning mentioned in the studies was satisfactory internet connectivity (Chan \& Wilson, 2020; Lassoued et al., 2020). This issue was particularly prevalent in remote areas of Middle East countries where internet connectivity is difficult and provides limited upload and download speeds (Lassoued et al., 2020). Platform access issues and software problems were also a concern for participants in Mouchantaf (2020)'s study of teacher perspectives of online learning in Lebanon, and Rizun and Strzelecki (2020)'s impact analysis of online learning in Poland. There is no one-sizefits all approach that will meet the diverse needs of learners from different disciplines across the globe. University administrations need to adopt flexible approaches to technology adoption that fully consider the unique circumstances of learners in specific locations and circumstances. The ongoing challenge for university communities is to identify and adapt new IT technologies and services to the management of knowledge and learning processes (Gros \& García-Peñalvo, 2016).

\subsubsection{Online competence}

Faculty and students have to be competent and confident in both pedagogical and technical aspects of teaching and learning online. In Lassoued et al. (2020)'s study on obstacles to online learning, the authors identify faculty competence in online assessment and student difficulties in adjusting to online learning as significant barriers to successful e-learning transition. This deficit in mastering online teaching and learning styles is compounded by a lack of faculty and student proficiency in the use of online technologies as discovered in the study on the digital competence of faculty and students at a Spanish university (Sales et al., 2020). This apparent deficit in digital literacy could be due to the absence of institutional support, as suggested in Mouchantaf (2020)'s study. Administrators should not only encourage educators to maintain proficiency in modern e-learning tools, but also provide opportunities to develop skills in best practice teaching and curriculum development for their discipline (Schmidt et al., 2016). This is encapsulated within the TPACK framework.

\subsubsection{Academic dishonesty}

A Chinese study of four universities revealed that plagiarism was an issue of concern for English language assessment in an online environment (Davies et al., 2020). The fact that many students are aware that copying work without attribution is wrong does not appear to deter many students (Sales et al., 2020). The challenge here for EAP teachers is how to deploy tools such as Turnitin and PeerMark to mitigate instances of online cheating. Davies et al. (2020) suggest that instances of plagiarism can be mitigated by providing students with more effective feedback on draft submissions. Cheating was also cited as a problem in online exams as teachers 
cannot readily verify the identity of each examination candidate (Lassoued et al., 2020; Sahbaz, 2020). Allowing students to control their environment is a challenge to assessment authenticity. One approach to mitigating attempts to commit academic dishonesty may be to employ a suite of technologies to both authenticate students and verify the originality and authenticity of their work. The TeSLA project, an adaptive trust-based e-assessment system, is an attempt to achieve this by deploying tools such as facial recognition, voice recognition, keystroke analysis, forensic analysis of writing, and plagiarism detection (Mellar et al., 2018). However, these technologies should not replace proactive measures to educate students on the ethical implications of committing academic misconduct.

\subsubsection{Privacy and confidentiality}

The security and confidentiality of data were cited as an area of concern (Lassoued et al., 2020). Internet Personal Assistant (IPA) were specifically mentioned as having the potential to violate user privacy (María Consuelo et al., 2020) although the device did have security features to authenticate users. Privacy of data exchanged within the Zoom environment was also an area of interest. Effective measures to protect privacy included the use of waiting rooms, user validation using passwords, and admitting users individually from waiting rooms once they had joined a session (Romero-Ivanova et al., 2020). The technological means to protect privacy by authenticating user access must also be backed up by guidelines on how stored data can be used. Issues of concern include data ownership, data sharing, consent to supply data, and maintaining anonymity are (Avella et al., 2016). Addressing these concerns should ideally take place prior to e-learning implementation rather than an hoc approach that resolves privacy issues as they arise.

\subsection{Lessons learned - the way forward}

\subsubsection{Institutional support}

It was clear from the examined studies that institutional support was vital to the success of transitioning to online learning (Alqahtani \& Rajkhan, 2020; Davies et al., 2020; Hartshorn \& McMurry, 2020; Kara et al., 2020; Tartavulea et al., 2020; Todd, 2020). The suggested support improvements could take many forms such as providing clarity on plans and decisions as they evolve (Davies et al., 2020), providing support resources for faculty and students struggling with transitional arrangements to online learning (Hartshorn \& McMurry, 2020), and paying for subscriptions for popular SM platforms used by faculty (Kara et al., 2020). It is unrealistic to expect faculty and students to seamlessly adapt to online learning spaces by repeating patterns of behaviour and processes that worked in a F2F situation. Institutional support at the very least should include the provisioning of appropriate support for technical issues related to online learning, training for both students and faculty to leverage online learning engagement opportunities, and a commitment to support 
the development of multi-media learning materials tailored to online environments (Kebritchi et al., 2017).

\subsubsection{Training}

As previously mentioned, training is an important component of both instructor and student success online. This is highlighted in Shawaqfeh et al. (2020)'s study of the online learning experiences of pharmacy students. This study revealed that both faculty and student training needs were highly associated with barriers to success in an online environment. This lack of digital literacy among faculty is also confirmed as an impediment toonline medical training in Jordan (Al-Balas et al., 2020). Training in specific technologies for both teachers and students was identified as a needed institutional support for ESL learners (Hartshorn \& McMurry, 2020). The need for simulation software training for teachers and self-management strategies for students was mentioned in Wang et al. (2020)'s study of medical student experiences with online learning in China. Finally, training for educators in the use of SM for educational purposes was cited as beneficial to its effective implementation in course delivery (Kara et al., 2020). While recognising that the COVID-19 pandemic provided no leeway for preparing faculty and students for their new learning environment, technologies and platforms such as Zoom, Moodle and Facebook have become almost ubiquitous among learners and are probably here to stay. Ongoing investment in faculty training to use these online platforms could help maintain high quality HE programs, even if they do eventually return to a F2F mode.

\subsubsection{Blended learning}

Despite the forced transition to online learning, there was a noticeable preference evident in many studies for some form of F2F instruction to be continued. This preference took the form of traditional classroom-based instruction (Garris \& Fleck, 2020; Mouchantaf, 2020; Rizun \& Strzelecki, 2020; Tartavulea et al., 2020) and blended learning options (Al-Balas et al., 2020; Alqahtani \& Rajkhan, 2020; Kaur et al., 2020; Liu et al., 2020). Blended learning can be viewed as a hybrid environment that combines the benefits of traditional F2F learning spaces while exploiting online technologies that enrich learning content and delivery options. A blended learning environment may be the best option for institutions post-COVID to leverage the lessons learned from the online experience while retaining the advantages of traditional F2F approaches. (Kaur et al., 2020). This also supports the need for the education sector to be able to respond to future crises should they occur. Liu et al. (2020)'s Chinese study on the sustainability of university learning postCOVID reinforces the need to enhance blended learning systems across Asia as a return to the old way of doing things is not desirable. The necessity of maintaining an effective online presence for all courses regardless of preferred delivery mode cannot be understated should a future shock incapacitate institutional capabilities to provide F2F instruction. 


\subsubsection{Learning communities}

Traditional classroom education fosters a social environment in which interpersonal interactions are crucial to the learning process (Alamri, 2016). Liu et al. (2020)'s study revealed that maintaining viable learning communities online was an important consideration for students. Another approach reported in the study of e-practicums in teacher training was to use online mentoring to create a community of learners (Ersin et al., 2020). An effective way of sustaining a sense of learning camaraderie online is to exploit the use of SM in online delivery. This is supported by the study on SM use to support learning and teaching (Kara et al., 2020) which highlights the benefits of SM in expanding learning communities beyond the constraints inherent in an established class. SM represents a powerful, inexpensive asynchronous communication option for faculty and institutions to engage with their students (Carr \& Hayes, 2015; Koshkin et al., 2016). It should not be discounted as a useful tool to enhance student interconnectedness.

\section{Practical implications}

This review has revealed some important concerns of learning communities that transitioned to online learning during the COVID-19 pandemic. First, a preference for person-to-person interactions between the primary stakeholders in education (teachers and students) was expressed in several studies and in some cases, even lamented. Moving forward, returning to some form of physical learning space would be preferable if circumstances permit. Second, the skills, motivation, and technology required to thrive in an online environment are distinctly different from the accustomed norms of classroom instruction. Third, a transition to online learning during the pandemic was generally accepted as the only viable option. Moving forward, the issue becomes how best to retain the features of traditional F2F instruction while building capacity to enhance learning with tools and technology that can be quickly deployed if a disruptor were to disrupt F2F activities in the future.

Rather than compartmentalising education into F2F, blended, and online learning options, this paper proposes that a more integrated view of learning would benefit HEIs by providing greater flexibility to adapt resources and processes to accommodate abrupt changes to the external environment such as those imposed during the pandemic. Figure 4 depicts a model that encapsulates the learning process within a modality-neutral learning space called the "Technology Enhanced Learning Hub". Impacting upon this learning space are three broad influencers that facilitate learning progress and shape how stakeholders interact with each other. The institution influencer represents the gatekeeper of educational resources that can be used to enhance stakeholder training, develop learning materials, and provide other needed support. The technology category includes technical capabilities to enable access to online systems and software, ensure privacy and security of data, and facilitate synchronous and asynchronous communication as required. The community influencer encompasses the interactions of key stakeholders themselves, and includes social media, academic integrity, and assessment. Importantly, the model does not 


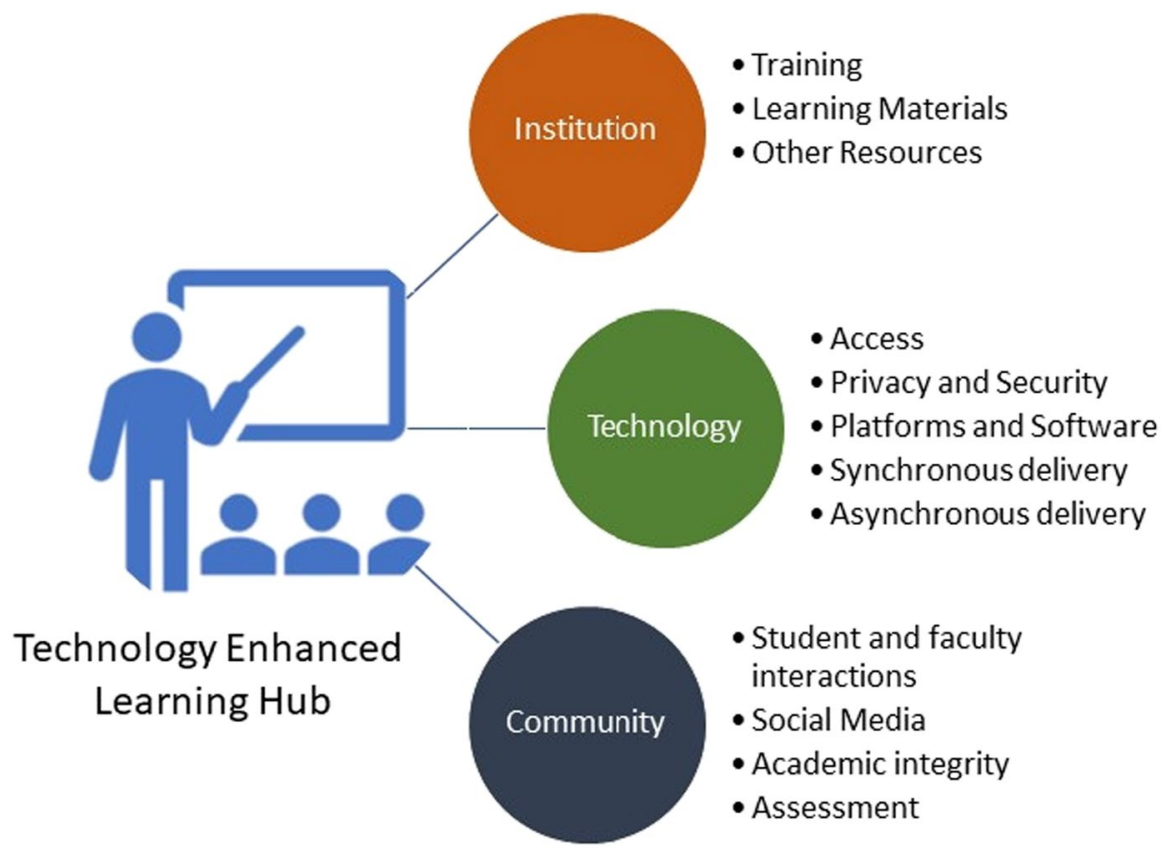

Fig. 4 Technology enhanced learning hub

assume a particular delivery or learning approach but instead seeks to leverage available technological, pedagogical, and institutional resources in a delivery-agnostic manner.

\section{Conclusion}

The advent of the pandemic fundamentally changed the way HEIs deliver education across the globe. In order to cope with restrictions on person-to-person interactions, HEIs have accelerated their transition to online learning with profound consequences for both students and faculty. This transition has been facilitated by the integration of online technologies such as Zoom and Moodle into course delivery systems which have in turn instigated changes to traditional F2F pedagogical practices to accommodate e-learning for different knowledge domains. This review has identified five important challenges to effective online transition: integrating synchronous and asynchronous tools into seamless online delivery, overcoming barriers to technology access, improving online competencies for learners and faculty, overcoming academic dishonesty issues in online assessment, and privacy and confidentiality. This review also identified four strategies that could be incorporated into a best practice framework for online education. First, institutional support should be visible and multifaceted with a particular focus on online learning materials development and technology support for faculty and students. Second, in order to mitgate the effects of any future crises, blended learning should be embraced as a mandatory 
component of F2F instruction in a post-COVID world. Third, training in educational technologies and their effective use should be available to faculty and students who need it. Last, the capacity for learners to participate in online learning communities needs to be enhanced to ensure that a similar sense of connectedness can be retained if programs transition to online-only modes of delivery. The findings of this study are limited by its focus on English-only publications during a time when the COVID-19 pandemic is still in full effect. It is hoped that the preliminary findings in this review will inspire more comprehensive global investigations into the impact of this once-in-a-lifetime global disruptor of higher education, and the lessons learned from the experience.

Author contributions All authors made an equal contribution to the manuscript.

Data availability There are no data sets and other materials to supply.

Code availability Not Applicable.

\section{Declarations}

Ethics approval Not applicable.

Consent to participate Not applicable.

Consent for publication Not applicable.

Conflicts of interest None of the authors have any conflicts interests to report.

\section{References}

Al-Balas, M., Hasan Ibrahim, A.-B., Jaber, H. M., Obeidat, K., Al-Balas, H., Aborajooh, E. A., Al-Taher, R., \& Al-Balas, B. (2020). Distance learning in clinical medical education amid COVID-19 pandemic in Jordan: Current situation, challenges, and perspectives. BMC Medical Education, 20, 1-7. https://doi.org/10.1186/s12909-020-02257-4.

Alamri, J. M. (2016). The perception of interpersonal relations between instructors and students as experienced within classroom and online communication: A mixed method case study of undergraduate women in a Saudi institution. PhD thesis. University of Nottingham. http://eprints.nottingham.ac.uk/ 37604/.

Alqahtani, A. Y., \& Rajkhan, A. A. (2020). E-Learning critical success factors during the COVID-19 pandemic: A comprehensive analysis of e-learning managerial perspectives. Education Sciences, 10(9), 216. https://doi.org/10.3390/educsci10090216.

Arasaratnam-Smith, L. A., \& Northcote, M. (2017). Community in online higher education: Challenges and opportunities. Electronic Journal of e-Learning, 15(2), 188-198.

Archambault, L. M., \& Barnett, J. H. (2010). Revisiting technological pedagogical content knowledge: Exploring the TPACK framework. Computers \& Education, 55(4), 1656-1662. https://doi.org/10. 1016/j.compedu.2010.07.009.

Avella, J. T., Kebritchi, M., Nunn, S. G., \& Kanai, T. (2016). Learning analytics methods, benefits, and challenges in higher education: A systematic literature review. Online Learning, 20(2), 13-29.

Bryson, J. R., \& Andres, L. (2020). Covid-19 and rapid adoption and improvisation of online teaching: Curating resources for extensive versus intensive online learning experiences. Journal of Geography in Higher Education, 44(4), 608-623. https://doi.org/10.1080/03098265.2020.1807478. 
Carr, C. T., \& Hayes, R. A. (2015). Social media: Defining, developing, and divining. Atlantic Journal of Communication, 23(1), 46-65. https://doi.org/10.1080/15456870.2015.972282.

Chan, C. B., \& Wilson, O. (2020). Using chakowa's digitally enhanced learning model to adapt faceto-face EAP materials for online teaching and learning. International Journal of TESOL Studies. https://doi.org/10.46451/ijts.2020.09.10.

Chugh, R., \& Ruhi, U. (2017). Social media in higher education: A literature review of Facebook. Education and Information Technologies, 23(2), 605-616. https://doi.org/10.1007/s10639-017-9621-2.

Chugh, R., \& Ruhi, U. (2019). Social Media for Tertiary Education. In Encyclopedia of Education and Information Technologies, 1-6. https://doi.org/10.1007/978-3-319-60013-0_202-1.

Collins, J. A., \& Fauser, B. C. J. M. (2005). Balancing the strengths of systematic and narrative reviews. Human Reproduction Update, 11(2), 103-104. https://doi.org/10.1093/humupd/dmh058.

Cox, S., \& Graham, C. R. (2009). Using an elaborated model of the TPACK framework to analyze and depict teacher knowledge. TechTrends, 53(5), 60-69.

Davies, J. A., Davies, L. J., Conlon, B., Emerson, J., Hainsworth, H., \& McDonough, H. G. (2020). Responding to COVID-19 in EAP contexts: A comparison of courses at four Sino-foreign universities. International Journal of TESOL Studies, 2(2), 32-52.

Ersin, P., Atay, D., \& Mede, E. (2020). Boosting preservice teachers' competence and online teaching readiness through e-practicum during the COVID-19 outbreak. International Journal of TESOL Studies, 2(2), 112-124.

Garris, C. P., \& Fleck, B. (2020). Student evaluations of transitioned-online courses during the COVID19 pandemic. Scholarship of Teaching and Learning in Psychology. https://doi.org/10.1037/st100 00229.

Gonzalez, T., Rubia, M. A. d. 1., Hincz, K. P., Comas-Lopez, M., Subirats, L., Fort, S., \& Sacha, G. M. (2020). Influence of COVID-19 confinement on students' performance in higher education. PLoS ONE, 15(10). https://doi.org/10.1371/journal.pone.0239490.

Gros, B., \& García-Peñalvo, F. J. (2016). Future trends in the design strategies and technological affordances of e-learning. In: Spector M., Lockee B., Childress M. (eds) Learning, Design, and Technology. Springer, Cham. https://doi.org/10.1007/978-3-319-17727-4_67-1.

Hartshorn, K. J., \& McMurry, B. L. (2020). The Effects of the COVID-19 pandemic on ESL learners and TESOL practitioners in the United States. International Journal of TESOL Studies, 2(2), 140-157.

Jang, S.-J., \& Tsai, M.-F. (2013). Exploring the TPACK of Taiwanese secondary school science teachers using a new contextualized TPACK model. Australasian Journal of Educational Technology, 29(4). https://doi.org/10.14742/ajet.282.

Janghorban, R., Latifnejad Roudsari, R., \& Taghipour, A. (2014). Skype interviewing: The new generation of online synchronous interview in qualitative research. International Journal of Qualitative Studies, 9, 24152. https://doi.org/10.3402/qhw.v9.24152.

Kara, N., Çubukçuoğlu, B., \& Elçi, A. (2020). Using social media to support teaching and learning in higher education: an analysis of personal narratives: Association for learning technology journal. Research in Learning Technology, 28. https://doi.org/10.25304/rlt.v28.2410.

Kaur, N., Dwivedi, D., Arora, J., \& Gandhi, A. (2020). Study of the effectiveness of e-learning to conventional teaching in medical undergraduates amid COVID-19 pandemic. National Journal of Physiology, Pharmacy and Pharmacology, 10(7), 563-567. https://doi.org/10.5455/njppp.2020.10.04096 202028042020.

Kebritchi, M., Lipschuetz, A., \& Santiague, L. (2017). Issues and challenges for teaching successful online courses in higher education. Journal of Educational Technology Systems, 46(1), 4-29. https:// doi.org/10.1177/0047239516661713.

Khalil, R., Mansour, A. E., Fadda, W. A., Almisnid, K., Aldamegh, M., Al-Nafeesah, A., Azzam, A., \& Al-Wutayd, O. (2020). The sudden transition to synchronized online learning during the COVID19 pandemic in Saudi Arabia: A qualitative study exploring medical students' perspectives. BMC Medical Education, 20, 1-10. https://doi.org/10.1186/s12909-020-02208-z.

Kohnke, L., \& Moorhouse, B. L. (2020). Facilitating synchronous online language learning through Zoom. RELC Journal. https://doi.org/10.1177/0033688220937235.

Koshkin, A. P., Rassolov, I. M., \& Novikov, A. V. (2016). Monitoring social media: Students satisfaction with university administration activities. Education and Information Technologies, 22(5), 24992522. https://doi.org/10.1007/s10639-016-9558-x.

Larasati, P., \& Santoso, H. (2017). Interaction Design Evaluation and Improvements of Cozora - A Synchronous and Asynchronous Online Learning Application. 2017 7Th World Engineering Education Forum (WEEF). 536-541. https://doi.org/10.1109/weef.2017.8467168. 
Lassoued, Z., Alhendawi, M., \& Bashitialshaaer, R. (2020). An exploratory study of the obstacles for achieving quality in distance learning during the COVID-19 pandemic. Education Sciences, 10(9), 232. https://doi.org/10.3390/educsci10090232.

Lim, F. P. (2017). An analysis of synchronous and asynchronous communication tools in e-learning. Advanced Science and Technology Letters, 143(46), 230-234. https://doi.org/10.14257/astl. 2017.143.46.

Liu, Y., Zhang, Y., Qiao, W., Zhou, L., \& Coates, H. (2020). Ensuring the sustainability of university learning: Case study of a leading Chinese university. Sustainability, 12(17), 6929. https://doi.org/10. 3390/su12176929.

Lowenthal, P. R., Dunlap, J. C., \& Snelson, C. (2017). Live synchronous web meetings in asynchronous online courses: Reconceptualizing virtual office hours. Online Learning, 21(4). https://doi.org/10. 24059/olj.v21i4.1285.

Mallett, R., Hagen-Zanker, J., Slater, R., \& Duvendack, M. (2012). The benefits and challenges of using systematic reviews in international development research. Journal of Development Effectiveness, 4(3), 445-455. https://doi.org/10.1080/19439342.2012.711342.

María Consuelo, S.-M., Marticorena-Sánchez, R., \& Ochoa-Orihuel, J. (2020). Effectiveness of using voice assistants in learning: A study at the time of COVID-19. International Journal of Environmental Research and Public Health, 17(15), 5618. https://doi.org/10.3390/ijerph17155618.

McDaniels, M., Pfund, C., \& Barnicle, K. (2016). Creating dynamic learning communities in synchronous online courses: One approach from the Center for the Integration of Research, Teaching and Learning (CIRTL). Online Learning, 20(1), 110-129.

Mellar, H., Peytcheva-Forsyth, R., Kocdar, S., Karadeniz, A., \& Yovkova, B. (2018). Addressing cheating in e-assessment using student authentication and authorship checking systems: Teachers' perspectives. International Journal for Educational Integrity, 14(1). https://doi.org/10.1007/ s40979-018-0025-x.

Mitchell, J. E. (2020). How do we think about labs and practical skills in an online context? In: Gibbs, B. \& Wood, G. C., eds. Emerging Stronger: Lasting Impact from Crisis Innovation. Godalming: Engineering Professors' Council. 35.

Mouchantaf, M. (2020). The COVID-19 pandemic: Challenges faced and lessons learned regarding distance learning in Lebanese higher education institutions. Theory and Practice in Language Studies, 10(10), 1259-1266. https://doi.org/10.17507/tpls.1010.11.

Ng , C. H. N. (2020). Communicative Language Teaching (CLT) through Synchronous Online Teaching in English Language Preservice Teacher Education. International Journal of TESOL Studies, 2(2), 62-73. https://doi.org/10.46451/ijts.2020.09.06.

Ngom, B., Guillermet, H., \& Niang, I. (2012). Enhancing Moodle for offline learning in a degraded connectivity environment. 2012 International Conference on Multimedia Computing and Systems.

Pew, S. (2007). Andragogy and pedagogy as foundational theory for student motivation in higher education. InSight: a Collection of Faculty Scholarship, 2, 14-25.

Pilli, O. (2014). LMS Vs. SNS: Can social networking sites act as a learning management systems. American International Journal of Contemporary Research, 4(5), 90-97.

Rimmer, W. (2020). Responding to the coronavirus with open educational resources. International Journal of TESOL Studies, 2(2), 17-32.

Rizun, M., \& Strzelecki, A. (2020). Students' Acceptance of the COVID-19 impact on shifting higher education to distance learning in Poland. International Journal of Environmental Research and Public Health, 17(18), 6468. https://doi.org/10.3390/ijerph17186468.

Romero-Ivanova, C., Shaughnessy, M., Otto, L., Taylor, E., \& Watson, E. (2020). Digital practices \& applications in a Covid-19 culture. Higher Education Studies, 10(3), 80-87. https://doi.org/10.5539/ hes.v10n3p80.

Sahbaz, A. (2020). Views and evaluations of university students about distance education during the COVID-19 pandemic. Educational Process: International Journal, 9(3), 185-198. https://doi.org/ 10.22521/edupij.2020.93.5.

Sales, D., Cuevas-Cerveró, A., \& Gómez-Hernández, J.-A. (2020). Perspectives on the information and digital competence of Social Sciences students and faculty before and during lockdown due to Covid-19. Profesional de la Información, 29(4). https://doi.org/10.3145/epi.2020.jul.23.

Schmidt, S. W., Tschida, C. M., \& Hodge, E. M. (2016). How faculty learn to teach online: What administrators need to know. Online Journal of Distance Learning Administration, 19(1), 1-10.

Shawaqfeh, M. S., Al Bekairy, A. M., Al-Azayzih, A., Alkatheri, A. A., Qandil, A. M., Obaidat, A. A., Al Harbi, S., \& Muflih, S. M. (2020). Pharmacy students perceptions of their distance online 
learning experience during the COVID-19 pandemic: A cross-sectional survey study. Journal of Medical Education and Curricular Development, 7, 2382120520963039. https://doi.org/10.1177/ 2382120520963039.

Subramanian, P., Zainuddin, N., Alatawi, S., Javabdeh, T., \& Hussin, A. (2014). A study of comparison between Moodle and blackboard based on case studies for better LMS. Journal of Information Systems Research and Innovation, 6, 26-33.

Tartavulea, C. V., Albu, C. N., Albu, N., Dieaconescu, R. I., \& Petre, S. (2020). Online teaching practices and the effectiveness of the educational process in the wake of the Covid-19 pandemic. Amfiteatru Economic, 22(55), 920-936. https://doi.org/10.24818/EA/2020/55/920.

Teng, D.C.-E., ChenKinshuk, N.-S., \& Leo, T. (2012). Exploring students' learning experience in an international online research seminar in the synchronous cyber classroom. Computers \& Education, 58(3), 918-930. https://doi.org/10.1016/j.compedu.2011.10.018.

Terenko, O., \& Ogienko, O. (2020). How to teach pedagogy courses online at university in COVID19 pandemic: Search for answers. Revista Romaneasca Pentru Educatie Multidimensionala, 12(1Sup2), 173-179. https://doi.org/10.18662/rrem/12.1sup2/261.

Todd, R. W. (2020). Teachers' perceptions of the shift from the classroom to online teaching. International Journal of TESOL Studies, 2(2), 4-17.

Torraco, R. J. (2016). Writing integrative literature reviews: Guidelines and examples. Human Resource Development Review, 4(3), 356-367. https://doi.org/10.1177/1534484305278283.

Turnbull D., Chugh R., Luck J. (2019) Learning Management Systems: An Overview. In: Tatnall A. (eds) Encyclopedia of Education and Information Technologies. Springer, Cham. https://doi.org/10.1007/ 978-3-319-60013-0_248-1.

Uzzaman, M. N., Jackson, T., Uddin, A., Rowa-Dewar, N., Chisti, M. J., Habib, G. M. M., Pinnock, H., \& Collaborators, R. (2020). Continuing professional education for general practitioners on chronic obstructive pulmonary disease: Feasibility of a blended learning approach in Bangladesh. BMC Family Practice, 21(1), 203. https://doi.org/10.1186/s12875-020-01270-2.

Wang, C., A'na, X., Wang, W., \& Wu, H. (2020). Association between medical students' prior experiences and perceptions of formal online education developed in response to COVID-19: A crosssectional study in China. BMJ Open, 10(10), 1-10. https://doi.org/10.1136/bmjopen-2020-041886.

Watts, L. (2016). Synchronous and asynchronous communication in distance learning: A review of the literature. Quarterly Review of Distance Education, 17(1), 23-32.

Wingo, N. P., Ivankova, N. V., \& Moss, J. A. (2017). Faculty perceptions about teaching online: Exploring the literature using the technology acceptance model as an organizing framework. Online Learning, 21(1), 15-35.

Publisher's note Springer Nature remains neutral with regard to jurisdictional claims in published maps and institutional affiliations. 